J. Amer. Soc. Hort. Sci. 127(6):963-970. 2002.

\title{
In Situ Estimation of Carbon Balance of In Vitro Sweetpotato and Tomato Plantlets Cultured with Varying Initial Sucrose Concentrations in the Medium
}

\author{
Chieri Kubota ${ }^{1}$ \\ Department of Plant Sciences, The University of Arizona, Tucson, AZ 85721-0036 \\ Makiko Ezawa and Toyoki Kozai
Department of Bioproduction Science, Chiba University, Matsudo, Chiba 271-8510, Japan
}

Sandra B. Wilson

Department of Environmental Horticulture, Indian River Research and Education Center, Institute of Food and Agricultural Sciences, University of Florida, 2199 South Rock Road, Fort Pierce, FL 34945-3138

\begin{abstract}
AdDitional INDEX wORDS. $\mathrm{CO}_{2}$ concentration, environmental control, Ipomoea batatas, Lycopersicon esculentum, photoautotrophic, photomixotrophic, photosynthesis, respiration, sugar

Abstract. The effects of initial sucrose (suc) concentrations in the medium $\left(S_{0}\right)$ on the carbon balance and growth of sweetpotato [Ipomoea batatas (L.) Lam. 'Beniazuma'] and tomato (Lycopersicon esculentum Mill. 'HanaQueen') plantlets were studied under controlled environmental conditions. Plantlets were cultured with $0,7.5,15$, or $30 \mathrm{~g} \cdot \mathrm{L}^{-1}$ of $S_{0}$ under high photosynthetic photon flux $\left(160\right.$ to $\left.200 \mu \mathrm{mol} \cdot \mathrm{m}^{-2} \cdot \mathrm{s}^{-1}\right)$ and $\mathrm{CO}_{2}$ enriched $\left(1400\right.$ to $\left.2050 \mu \mathrm{mol} \cdot \mathrm{mol}^{-1}\right)$ conditions. Net photosynthetic rate per leaf area $\left(P_{l}\right)$ decreased and dry weight per plantlet $\left(W_{d}\right)$ increased with increasing $S_{0}$, but did not differ significantly between $S_{0}$ of 7.5 to $30 \mathrm{~g} \cdot \mathrm{L}^{-1}$ for sweetpotato or 15 to $30 \mathrm{~g} \cdot \mathrm{L}^{-1}$ for tomato. Carbon influxes and effluxes of the plantlets by metabolism of medium suc and/or photosynthesis, and respiration were estimated based on measurements of in situ and steady state $\mathrm{CO}_{2}$ exchange rates and sugar uptake during culture. At $S_{0}$ from 7.5 to $30 \mathrm{~g} \cdot \mathrm{L}^{-1}$, photosynthesis was responsible for $82 \%$ to $92 \%$ and $60 \%$ to $67 \%$ of carbohydrate assimilation for sweetpotato and tomato, respectively. Estimated carbon balances of plantlets based on the estimated and actual increases of moles of carbon in plant tissue demonstrated that in situ estimation of carbon balance was reasonably accurate for sweetpotato at $S_{0}$ of 0 to $15 \mathrm{~g} \cdot \mathrm{L}^{-1}$ and for tomato at $S_{0}$ of $0 \mathrm{~g} \cdot \mathrm{L}^{-1}$ and that the actual contribution of photosynthesis for tomato at high $S_{0}$ might be lower than the values estimated in the present experiment. Results showed that initial suc concentration affected the relative contribution of photosynthesis on their carbon balances and that the responses were species specific. The failure of validation at $S_{0}$ in a range specific to each species suggested the need for further study on carbon metabolism of in vitro plantlets cultured with sugar in the medium.
\end{abstract}

In vitro plant culture environments are recognizably different from greenhouse or field environments. The uniqueness includes the presence of sugar in the medium and use of the relatively airtight vessels, which results in the accumulation of ethylene and water vapor, and the accumulation or depletion of $\mathrm{CO}_{2}$. Measurement of $\mathrm{CO}_{2}$ concentration inside vessels containing chlorophyllous plantlets showed that $\mathrm{CO}_{2}$ concentrations inside the vessel dropped below ambient levels and often fell as low as the $\mathrm{CO}_{2}$ compensation point during the light period (Desjardins et al., 1988; Fournioux and Bessis, 1986; Fujiwara et al., 1987; Infante et al., 1989; Kozai and Sekimoto, 1988). Therefore, regardless of their photosynthetic ability, chlorophyllous plantlets grown in vitro are required to grow photomixotrophically; supported by relatively large amounts of available sugar in the medium and limited $\mathrm{CO}_{2}$. Such a physiological phenomenon of having two carbon sources (photomixotrophy) is not the norm for ex vitro plants, except for parasitic plants, such as Striga hermonthica (Del.) Benth. (Pageau et al., 1998). Consequently, the in vitro environment serves as a unique model for studies focusing on photosynthesis and carbon metabolism. A quantitative understanding of the relative contribution of each carbon source gives important information on the carbon metabolism of in vitro plants.

For more practical reasons, a quantitative understanding of sugar

Received for publication 3 Jan. 2002. Accepted for publication 21 Aug. 2002. We thank Nicca Chemical Co. Ltd., Japan, for providing plant materials and the Japan Society for the Promotion of Science for financial support.

${ }^{1}$ Corresponding author; e-mail ckubota@ag.arizona.edu. uptake and photosynthesis is necessary to enhance plantlet growth with a minimal input of energy and other resources, thereby maximizing the biomass production efficiency. Reducing suc concentration in the medium and increasing photosynthetic photonflux $(P P F)$ and $\mathrm{CO}_{2}$ concentration in the headspace have reportedly enhanced net photosynthetic rates and growth of plantlets (Kozai, 1991). However, increasing the medium suc concentration may increase dry matter accumulation of the plantlets. When growth promotion is attempted while minimizing production costs, a decision must be made whether one should promote plantlet photosynthesis by controlling light and $\mathrm{CO}_{2}$ levels, or enhancing carbon uptake from the medium by increasing the sugar supply, or both.

In vitro photosynthesis has been measured many ways including an in situ measurement method based on $\mathrm{CO}_{2}$ balance in the vessel and the use of open flow or closed measurement systems, as reviewed by Desjardins et al. (1995). The in situ measurement method of net photosynthetic rates (Fujiwara et al., 1987; Fujiwara and Kozai, 1995) is preferred over open flow or closed measurement systems, to minimize the possible disturbance of the in vitro environment. For photomixotrophically cultured plantlets, net photosynthetic rates give a limited assessment of plantlet carbon balance because plantlets use sugar in the medium as carbon source in addition to $\mathrm{CO}_{2}$. Moreover, net photosynthetic rates measured as $\mathrm{CO}_{2}$ exchange rates include dark respiration rates which dissimilate sugar absorbed from the medium (Fujiwara et al., 1995). To optimize the environmental conditions for photomixotrophic plantlets, it is necessary to determine their carbon balance with each 
carbon flux (influx and efflux) under various environments.

The carbon balance of photomixotrophic and photoautotrophic plantlets has been studied for rose, Rosa multiflora L. (De Riek et al., 1991); potato, Solanum tuberosum L. (Fujiwara et al., 1995; Wolf et al., 1998); and gardenia, Gardenia jasminoides Ellis. (Serret et al., 1996, 1997) using several different methods. De Riek et al. (1991) quantified components of plantlet carbon flow (net carbon fixed by photosynthesis, carbon released by respiration, and medium carbohydrate accumulated in dry weight and respired as $\mathrm{CO}_{2}$ ) using ${ }^{14} \mathrm{C}$ labeled suc and ${ }^{14} \mathrm{CO}_{2}$. Use of carbon isotopes can be straightforward for determining carbon influx and efflux separately, and the proportion of tissue carbon originating from different sources. However, the analysis requires specially designed vessels or chambers and use of radioisotopes, limiting practical application of the method.

Serret et al. $(1996,1997)$ used a stable carbon isotope $\left({ }^{13} \mathrm{C}\right)$ and estimated the percentage of carbon in leaflet tissue originating from photosynthesis. A similar method using ${ }^{13} \mathrm{C}$ to evaluate the "degree of photoautotrophy" in terms of percent tissue carbon derived from photosynthesis has also been tested (Wolf et al., 1998). Use of ${ }^{13} \mathrm{C}$ is suitable for in situ evaluation of carbon balance without altering culture conditions. However, percentages of carbon originating from photosynthesis and medium sugar over the total carbon in the plantlet (residuals after respiratory carbon loss) may not provide enough information for understanding the contribution of photosynthesis in photomixotrophic plantlet growth. Because the culture vessel represents a relatively closed system, carbon from the metabolism of medium suc in plantlets through respiration may be refixed by photosynthesis, resulting in a low estimate of degree of plantlet photoautotrophy (Serret et al., 1996). Furthermore, most sugar absorbed from the medium was reportedly released as $\mathrm{CO}_{2}$, resulting in small amounts of carbon originating from medium sugar accumulating in the plantlets as indicated in the study using ${ }^{14} \mathrm{C}$-suc (Borkowska and Kubik, 1990; De Riek et al., 1991).

To understand photomixotrophic growth of plantlets under different culture conditions, a quantitative approach for determining carbon influx by photosynthesis and sugar uptake is necessary. Fujiwara et al. (1995) developed a culture system where plantlet $\mathrm{CO}_{2}$ exchange rates were continuously measured by employing forced ventilation in the vessel. This method required a number of assumptions to estimate the gross photosynthetic rate from $\mathrm{CO}_{2}$ exchange rates during light and dark periods, but alternatively, allowed the estimation of carbon influx from photosynthesis. Unfortunately, forced ventilation disturbs the culture environment, resulting in misleading interpretation of results. To estimate carbon exchange in culture systems using natural ventilation, in situ measurement of $\mathrm{CO}_{2}$ exchange rates is preferred over methods which use forced ventilation. The objectives of our research were to determine the effects of initial suc concentration $\left(S_{0}\right)$ on in situ plantlet carbon balance estimated by in situ and steady state $\mathrm{CO}_{2}$ exchange rates and medium sugar concentration.

\section{Materials and Methods}

Culture conditions. Sweetpotato (Ipomoea batatas, 'Beniazuma') and tomato (Lycopersicon esculentum, 'HanaQueen') were selected as model plants because both species have been micropropagated using photoautotrophic conditions (AfreenZobayed et al., 1999; Kubota et al., 2001). Culture conditions selected were specific for each species. Sweetpotato single node cuttings with a leaf (FW: $80 \pm 15 \mathrm{mg}$ ) and tomato terminal shoots (FW: $80 \pm 15 \mathrm{mg}$ ) were cultured for 20 and $15 \mathrm{~d}$, respectively. Cylindrical polycarbonate vessels (volume: $480 \mathrm{~mL}$ ) and lids (Nicca
Chemical Co. Ltd., Fukui, Japan) were modified by drilling two holes $(10 \mathrm{~mm}$ in diameter) in addition to the original hole $(8 \mathrm{~mm}$ in diameter) for each lid and covering the holes each with a gas permeable membrane disk (pore size $0.5 \mathrm{~mm}$; Milliseal, Millipore Japan). The number of air exchanges of the vessel (Kozai et al., 1986) was increased accordingly on days 6 and 11 by removing adhesive plastic tape that covered the gas permeable membrane disks, resulting in 1.3 (days 0 to 5), 1.9 (days 6 to 10), and 4.7 (days 11 to 20 ) air exchanges/h for sweetpotato; 1.3 (days 0 to 5) and 4.7 (days 6 to 15) air exchanges $/ \mathrm{h}$ for tomato. Suc was added to the Murashige and Skoog (1962) medium at $0,7.5,15$, or $30 \mathrm{~g} \cdot \mathrm{L}^{-1}$ before adjusting the $\mathrm{pH}$ (5.7 for sweetpotato; 5.9 for tomato). Vessels containing the liquid medium (100 $\mathrm{mL}$ per vessel) and cellulose plugs (20 plugs per vessel; Sorbarod, Baumgartner Papiers SA, Switzerland) were autoclaved for $20 \mathrm{~min}$ at $120^{\circ} \mathrm{C}$.

After transferring explants, vessels were placed under fluorescent tubes (FPL27EX-N, Matsushita Electric Co., Osaka, Japan) mounted horizontally above the shelf inside a growth chamber (AEL-3280, Advantec Co., Tokyo). The PPF was adjusted to 100 (days 0 to 10 ) and 200 (days 11 to 20 ) $\mu \mathrm{mol} \cdot \mathrm{m}^{-2} \cdot \mathrm{s}^{-1}$ for sweetpotato; 100 (days 0 to 5) and 160 (days 6 to 15 ) $\mu \mathrm{mol} \cdot \mathrm{m}^{-2} \cdot \mathrm{s}^{-1}$ for tomato under a $16 \mathrm{~h} \cdot \mathrm{d}^{-1}$ light period. Air temperatures inside the vessel during the light/dark period were $28.0 / 27.0{ }^{\circ} \mathrm{C}$ for sweetpotato and $24.0 / 23.0^{\circ} \mathrm{C}$ for tomato, respectively, and were monitored by a $0.1-$ mm copper-constantan thermocouple inserted into a vessel placed in the center of the shelf. Relative humidity in the culture room ranged from $70 \%$ to $80 \%$. The $\mathrm{CO}_{2}$ concentration in the culture room was enriched to 1400,1800 , and $2000 \mu \mathrm{mol} \cdot \mathrm{mol}^{-1}$ on days 0 to 5 , 6 to 10 , and 11 to 20 , respectively, for sweetpotato; $2050 \mu \mathrm{mol} \cdot \mathrm{mol}^{-1}$ on days 0 to 15 for tomato.

GROWTH MEASUREMENTS. Initial fresh weight was measured for each explant and initial dry weight of the explant $\left(W_{0}\right)$ was estimated using the percent dry matter over the fresh weight obtained from 10 explants sampled separately. Dry weight was measured after drying fresh samples at $80{ }^{\circ} \mathrm{C}$ for more than $48 \mathrm{~h}$. Plantlet fresh and dry weights and leaf areas were recorded $15 \mathrm{~d}$ (tomato) and $20 \mathrm{~d}$ (sweetpotato) after the start of the experiment. Leaf area was measured using image analysis software (LIA32, Nagoya University) on black and white images that were photocopied when harvested. The change in dry weight was calculated for each plantlet by subtracting $W_{0}$ from the final dry weight per plantlet $\left(W_{d}\right)$, and converted into mole carbon per plantlet $\left(D_{d}\right)$ with an assumption that $90 \%$ of dry matter was equivalent to carbohydrate $\left[\left(\mathrm{CH}_{2} \mathrm{O}\right)_{n}\right]$ (Murayama et al., 1984).

Sugar CONCENTRation OF THE MEDIUM. After autoclaving the medium, and harvesting plantlets, $10 \mathrm{~mL}$ of medium was sampled from each vessel and filtered through a $0.22 \mu \mathrm{m}$ (pore size) membrane. Concentrations of suc, glucose (gluc), and fructose (fruc) in the sampled media were measured using a HPLC with a refractive index detector (L6000, Hitachi Ltd., Tokyo) and a Gelpack GLC611 column (Hitachi Chemical Co., Tokyo) maintained at $70{ }^{\circ} \mathrm{C}$. Quantification was determined using a D-2000 Chromato-Integrator (Hitachi Ltd., Tokyo) and regression equations describing the suc, gluc, and fruc calibration lines. Prior to sampling the medium, each vessel was weighed. Medium volume was calculated from specific mass of the medium $\left(\mathrm{g} \cdot \mathrm{L}^{-1}\right)$ and the mass of the medium obtained by subtracting mass of plantlets, dried plugs, and empty vessel from the total mass of the vessel.

The absorbed mass of sugar per plantlet was calculated from sugar concentrations and medium volume, and was converted to absorbed mole carbon through sugar uptake from the medium $\left(U_{s}\right.$, mol C/plantlet): 
$U_{s}=\left\{\mathrm{n}_{\mathrm{s}} \times S_{0} / \mathrm{M}_{\mathrm{s}} \times V(0)-\left[\mathrm{n}_{\mathrm{s}} \times S_{s}(t) / \mathrm{M}_{\mathrm{s}}+\mathrm{n}_{\mathrm{g}} \times S_{g}(t) / \mathrm{M}_{\mathrm{g}}+\mathrm{n}_{\mathrm{f}} \times S_{f}(t) /\right.\right.$ $\left.\left.\mathrm{M}_{\mathrm{f}}\right] \times V(t)\right\} \times 1 / \mathrm{N}$

where, $\mathrm{n}_{\mathrm{s}}, \mathrm{n}_{\mathrm{g}}$, and $\mathrm{n}_{\mathrm{f}}$ are mole carbon per mole of suc, gluc, and fruc $\left(\mathrm{n}_{\mathrm{s}}=12\right.$, and $\left.\mathrm{n}_{\mathrm{g}}=\mathrm{n}_{\mathrm{f}}=6\right) ; S_{0}$ is the initial suc concentration of the medium before autoclaving $\left(0,7.5,15\right.$, or $\left.30 \mathrm{~g} \cdot \mathrm{L}^{-1}\right) ; S_{s}(t), S_{g}(t)$, and $S_{f}(t)$ are suc, gluc, and fruc concentrations $\left(\mathrm{g} \cdot \mathrm{L}^{-1}\right)$ on day $t ; \mathbf{M}_{\mathrm{s}}, \mathrm{M}_{\mathrm{g}}$, and $\mathrm{M}_{\mathrm{f}}$ are molecular mass of suc, gluc, and fruc $\left(\mathrm{g} \cdot \mathrm{mol}^{-1}\right) ; V(0)$ and $V(t)$ are medium volume per vessel on days $0(0.1 \mathrm{~L})$ and $t ; N$ is the number of plantlets per vessel. Total moles of carbon originating from suc added per vessel was assumed to be unchanged during autoclaving.

Carbon dioxide CONCENTRation InSIDE THE VeSSEL AND $\mathrm{CO}_{2}$ EXCHANGE RATE. Carbon dioxide concentrations inside and outside of the vessel $\left(C_{\text {in }}\right.$ and $C_{\text {out }}$, respectively $)$ were measured for a $0.25 \mathrm{~mL}$ gas sample using a gas chromatograph with a flame ionized detector and a reaction furnace for converting $\mathrm{CO}_{2}$ into $\mathrm{CH}_{4}$ (GC-9A, Shimadzu Co., Osaka, Japan). Measurements were made during light and dark periods every $5 \mathrm{~d}$ when the $C_{\text {in }}$ and $C_{\text {out }}$ were considered stable (steady state conditions). Net photosynthetic rate $\left(P_{n}\right)$ and dark respiration rate $\left(R_{d}\right)$ per plantlet were calculated as described by Fujiwara et al. (1987) and Fujiwara and Kozai (1995).

Carbon MOLES TAKEN UP AND RELEASEd BY PLANTLET $\mathrm{CO}_{2}$ EXCHANGES. Plantlet $\mathrm{CO}_{2}$ exchange rates during culture were estimated based on the simulated changes in $C_{i n}$ as described below. The $C_{\text {in }}$ under steady state conditions $\left(C_{i n, s}\right)$ during light and dark periods of each day were predicted for each vessel by fitting $C_{i n, s}$ on days $0,5,10,15$, and 20 with time in days using polynomial equations. The $C_{i n, s}$ on day 0 was given as median of the $C_{i n, s}$ on day 5 and the $C_{\text {out }}$ during light and dark periods. Diurnal changes of $C_{i n}$ were simulated for each day, assuming that $C_{i n}$ at the onset of the light period was equal to $C_{i n, s}$ of the previous dark period, and that it decreased linearly and reached a steady state value $2 \mathrm{~h}$ after onset of the light period. These assumptions on changes of $C_{i n}$ during the culture period were based on the previous observations on diurnal and periodic changes in $C_{i n}$ of the vessels containing plantlets (Fujiwara et al., 1987; Fujiwara and Kozai, 1995; Kozai and Sekimoto, 1988; Kubota et al., 2001). The cumulative $\mathrm{CO}_{2}$ exchange rate during the light period was estimated by integrating the difference of $C_{\text {out }}$ and $C_{\text {in }}$ over light period according to the dynamic and steady state methods for estimation of in vitro $\mathrm{CO}_{2}$ exchange rate (Fujiwara at al., 1987; Fujiwara and Kozai, 1995). The $R_{d}$ was calculated using $C_{i n, s}$ during the dark period. Cumulative $\mathrm{CO}_{2}$ exchange rate during the dark period was estimated as $R_{d}$ multiplied by dark period $(8 \mathrm{~h})$ assuming that $R_{d}$ remained constant during the dark period.

Moles of carbon fixed through photosynthesis and released through dark respiration and photorespiration during culture periods were estimated from the cumulative $\mathrm{CO}_{2}$ exchange rate during light and dark periods, according to the following assumptions: 1) gross photosynthetic rate $\left(P_{g}\right)$ is the sum of $P_{n}, R_{d}$, and photorespiration rate $\left.\left(R_{p}\right), 2\right) R_{d}$ is constant throughout the day, and 3) $R_{p}$ is equivalent to $15 \%$ of $P_{g}$.

Estimates of moles of carbon fixed through photosynthesis and released through respiration involved a number of assumptions based on typical diurnal changes in $\mathrm{CO}_{2}$ concentration inside vessels containing photosynthetically active plantlets. Therefore, validation of this method was made by comparing increases in moles of carbon per plantlet estimated from the carbon balance and those derived from the actual dry weight increase of the plantlets. Carbon balance of in vitro plantlets was expressed as follows:

$U_{s}+U_{p}-L_{d}-L_{p}-D_{b}=0$

where, $U_{p}$ is carbon absorbed during photosynthesis (mol C/plantlet); $L_{d}$ and $L_{p}$ are carbon released during dark respiration and photorespiration (mol C/plantlet), respectively; and $D_{b}$ is the carbon increase in plantlet tissue $\left(\mathrm{mol} \mathrm{C} /\right.$ plantlet). The percentage of $U_{p}$ over the sum of $U_{s}$ and $U_{p}$ was calculated and expressed as percent

Fig. 1. Dry weight and net photosynthetic rate per leaf area during the light period of sweetpotato on day 20 (A) and of tomato on day 15 (B), as affected by initial sucrose concentration $\left(0,7.5,15\right.$, or $\left.30 \mathrm{~g} \cdot \mathrm{L}^{-1}\right)$. $\mathrm{L}^{\mathrm{Ns}}, \mathrm{L}^{*}, \mathrm{~L}^{* *}, \mathrm{Q}^{\mathrm{Ns}}, \mathrm{Q}^{*}, \mathrm{Q}^{* *}=$ nonsignificant or significant linear $(\mathrm{L})$ or quadratic $(\mathrm{Q})$ response at $P \leq 0.05$ or 0.01 , respectively.

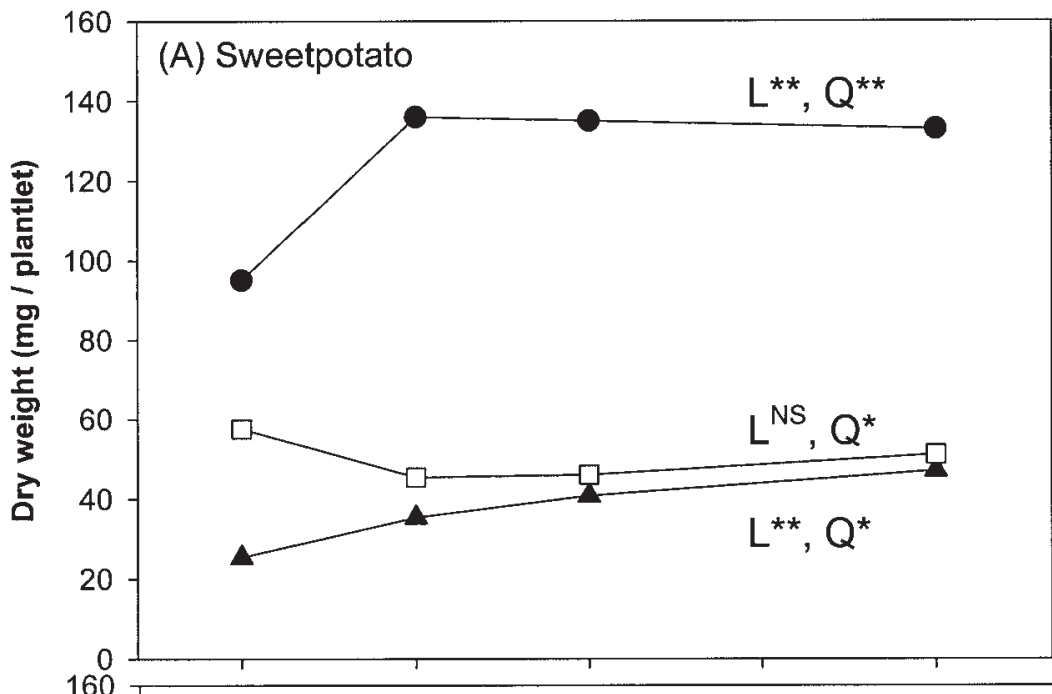

2.5

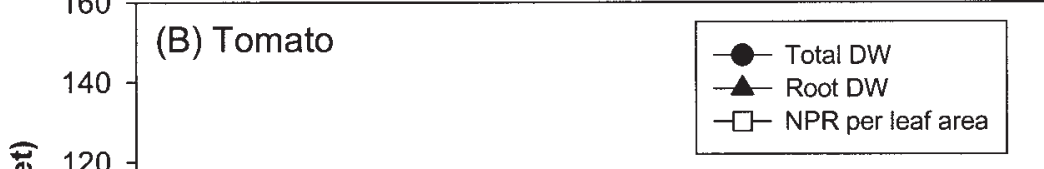




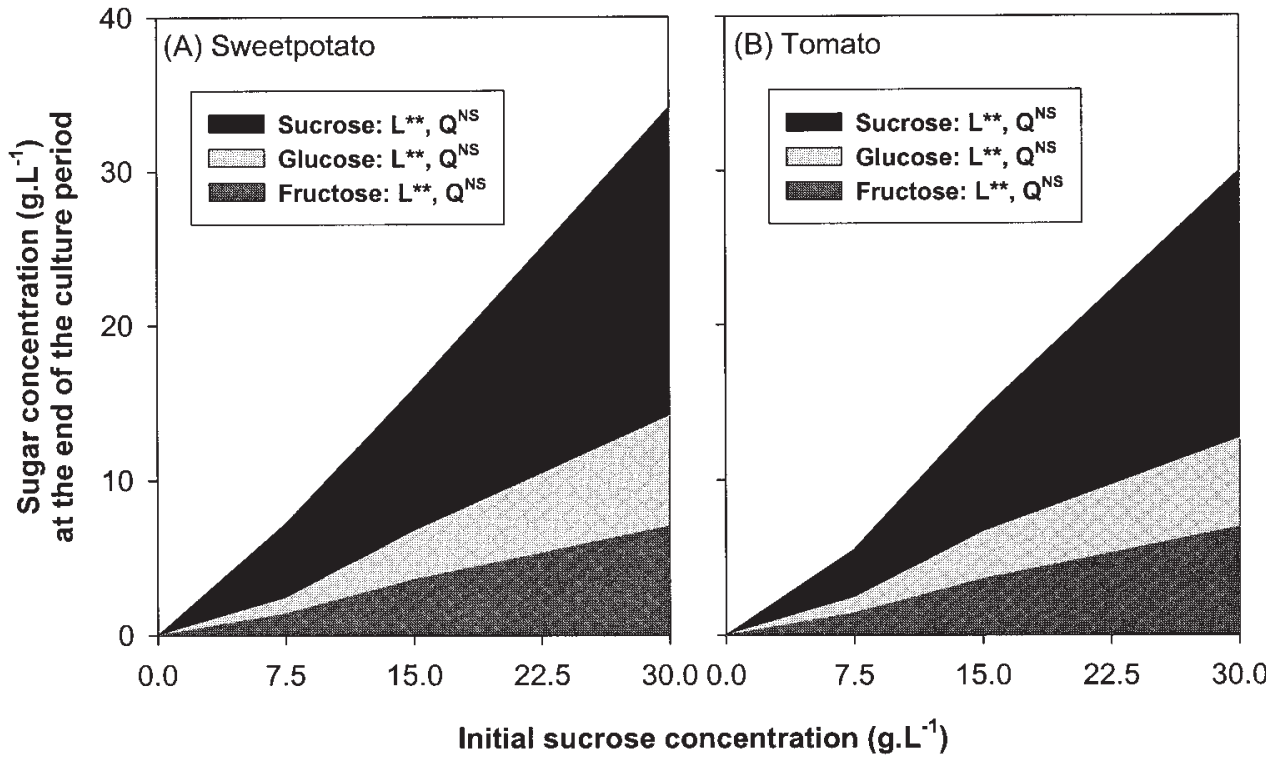

the Statistical Analysis System (Version. 6.12, SAS Institute).

\section{Results and Discussion}

Plantlet growth and Net PhotoSYNTHETIC RATE. Total $\left(W_{d}\right)$ and root dry weight of sweetpotato and tomato plantlets increased whereas net photosynthetic rate per leaf area $\left(P_{l}\right)$ decreased when suc was added to the medium (Fig. 1). The dry weight and net photosynthetic rate of the plantlets cultured without sugar in the medium $\left(S_{0}=0\right)$ may be further enhanced at a higher $\mathrm{CO}_{2}$ concentration and $P P F$ more favorable to photosynthesis.

For sweetpotato plantlets, $W_{d}$ increased and $P_{l}$ decreased with addition of suc to the medium, but both stabilized at $S_{0}$ greater than $7.5 \mathrm{~g} \cdot \mathrm{L}^{-1}$ (Fig.

Fig. 2. Final sucrose, glucose, and fructose concentrations $\left(\mathrm{g} \cdot \mathrm{L}^{-1}\right)$ for sweetpotato (A) and tomato (B) plantlets as affected by initial sucrose concentration $\left(S_{0}\right)$. $\mathrm{L}^{\mathrm{Ns}}$, $\mathrm{L}^{*}, \mathrm{~L}^{* *}, \mathrm{Q}^{\mathrm{Ns}}, \mathrm{Q}^{*}, \mathrm{Q}^{* *}=$ nonsignificant or significant linear $(\mathrm{L})$ or quadratic $(\mathrm{Q})$ response at $P \leq 0.05$ or 0.01 , respectively.

contribution of photosynthesis $\left[\% P ; \% P=U_{p} /\left(U_{s}+U_{p}\right)\right]$. The $D_{b}$, estimated by solving Eq. [2], was compared with the increase of moles of carbon in dry weight $\left(D_{d}\right)$.

STATISTICAL ANALYSIS. There were five and six vessels for each treatment in experiments using tomato and sweetpotato plantlets, respectively. Vessels containing four plantlets were considered replicates. Experiments for sweetpotato and tomato were conducted separately each with a completely randomized experimental design. All data within each experiment were subjected to analysis of variance (ANOVA), and effects of initial suc concentration were analyzed by partitioning into orthogonal multiple contrasts using
1A). For tomato plantlets, $W_{d}$ and $P_{l}$ stabilized around 15 to 30 $\mathrm{g} \cdot \mathrm{L}^{-1}$ of $S_{0}$. The increase of $W_{d}$ was associated with the decrease of $P_{l}$, probably because the plantlets had greater relative carbon influx from sugar in the medium at higher $S_{0}$. Decreased photosynthetic activities due to the sugar added to the medium have been reported with many species (Cristea et al., 1999; Kozai, 1991; Pospisilova et al., 1992). Langford and Wainwright (1987) demonstrated that decreasing the medium suc concentration $\left(10,20\right.$ or $\left.40 \mathrm{~g} \cdot \mathrm{L}^{-1}\right)$ increased the net photosynthetic rate of in vitro grown shoots for two rose cultivars (Rosa hybrid). Net photosynthetic rate per leaf area of tomato plantlets was about $60 \%$ lower with $30 \mathrm{~g} \cdot \mathrm{L}^{-1}$ than with no suc when examined under similar culture conditions as in the present experiment (Kubota et al., 2001).

The biochemical aspect of depression of photosynthesis by sugar in the medium has been extensively studied. Cappellades et al.

Table 1. $\mathrm{CO}_{2}$ concentrations $\left(C_{i n}, \mu \mathrm{mol} \cdot \mathrm{mol}^{-1}\right)$ inside the vessel during light and dark periods measured under steady state conditions on days 5 , 10 , 15 , and 20 (day-20 measurement was for sweetpotato plantlets only) as affected by initial sucrose concentration of the medium $\left(S_{0}\right)$. Simulation of the diurnal change of $\mathrm{CO}_{2}$ concentration inside the vessel and the subsequent estimation of cumulative $\mathrm{CO}_{2}$ exchange rates were made using the values obtained for each replication.

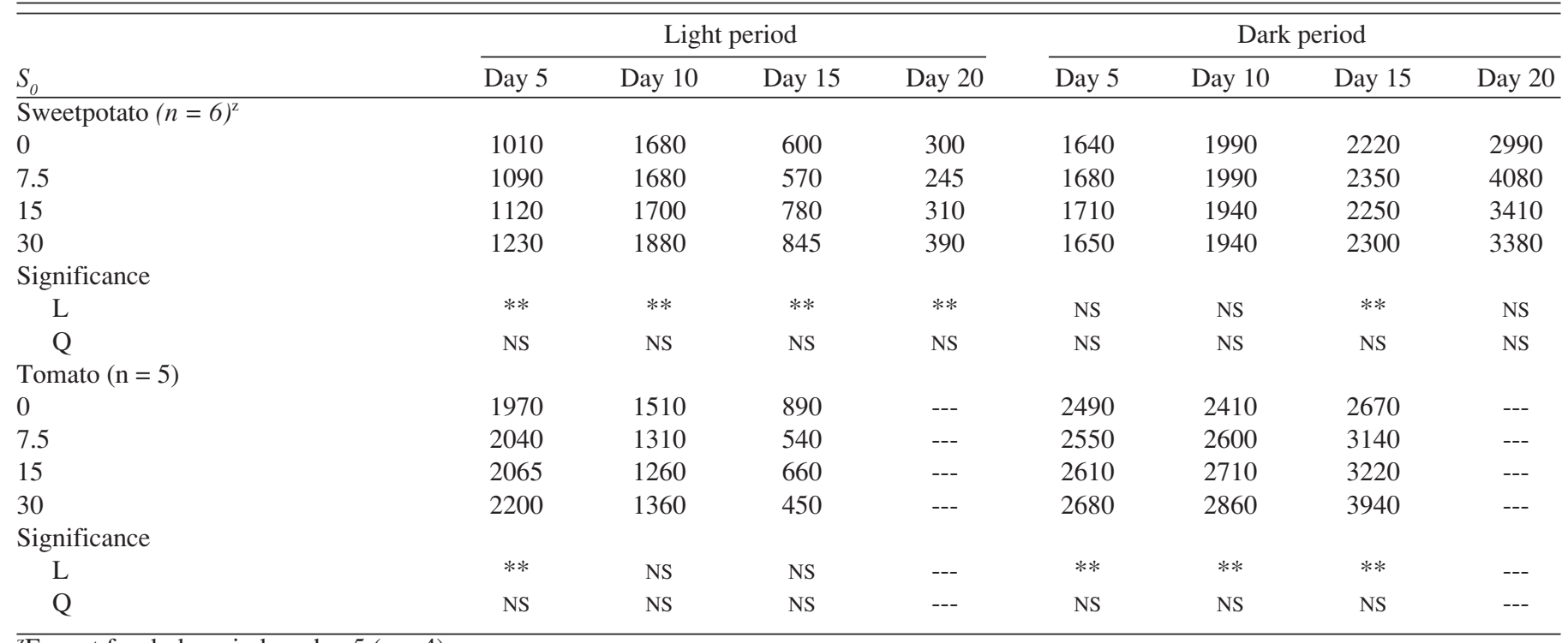

${ }^{\mathrm{z}}$ Except for dark period on day $5(\mathrm{n}=4)$.

${ }^{*, * *}$ Significance at $P \leq 0.05$ or 0.01 , respectively; L or Q indicates linear or quadratic response, respectively. 
(1991) showed that rose plantlets grown on a high suc concentration $\left(50 \mathrm{~g} \cdot \mathrm{L}^{-1}\right)$ medium had high accumulation of starch in the leaves resulting in reduced photosynthesis. Accumulation of carbohydrate in leaves has a strong correlation with inhibition of $\mathrm{CO}_{2}$ assimilation, although the exact mechanism is not known (Foyer and Galtier, 1996). Wilson et al. (2000) demonstrated potential differences in carbohydrate status between tomato and sweetpotato plantlets cultured under similar culture conditions. They reported that leaves of tomato plantlets cultured with $30 \mathrm{~g} \cdot \mathrm{L}^{-1}$ suc had significantly higher soluble sugar (suc, gluc, and fru) and starch concentrations than those without sugar in the medium, but that leaves of sweetpotato with and without sugar in the medium did not show significant differences in soluble sugar and starch concentrations. Desjardins et al. (1995) suggested that the most probable cause of reduced photosynthesis with sugar in the medium was on a series of biochemical reactions leading to the down-regulation or feedback inhibition of ribulose bisphosphate carboxylase (rubisco). In the present experiment, reduction of $P_{l}$ observed for sweetpotato plantlets may have been caused by enzymatic activities mediated by sugar absorbed from the medium rather than carbohydrate accumulation in the leaves, assuming that carbohydrate did not accumulate in the sweetpotato leaves with sugar in the medium as found by Wilson et al. (2000). For tomato, both increased carbohydrate levels and limited rubisco activities remain as possible reasons for a reduction of net photosynthetic rate. Further biochemical analyses will be needed to determine the actual limiting factor of photosynthesis at high $S_{0}$ for these species.

Root growth increased with increasing $S_{0}(P$ linear $\leq 0.01 ; P$ quadratic $\leq 0.05$ ) (Fig. 1). Shoot to root dry weight ratio was 2.8, 2.9, 2.3, and 1.8 for sweetpotato; and 3.1, 2.6, 2.3, and 2.0 for tomato at $S_{0}$ of $0,7.5,15$, and $30 \mathrm{~g} \cdot \mathrm{L}^{-1}$, respectively, indicating that more carbohydrate was allocated to roots with increasing $S_{0}$ in both species. Accumulation of soluble sugar and starch in roots was reported for sweetpotato and tomato plantlets cultured with 30 $\mathrm{g} \cdot \mathrm{L}^{-1}$ suc in the medium as compared with no suc (Wilson et al., 2000). High total soluble sugars were observed in leaf and root tissue of tomato and in root tissue of sweetpotato when cultured with $30 \mathrm{~g} \cdot \mathrm{L}^{-1}$ suc (Wilson et al., 2000). Piqueras et al. (1998) reported that Calathea luisae Gagnep. plantlets had higher starch concentration in roots and stems than in leaves, while suc concentration was highest in the stems, followed by leaves and roots. Although root dry weight of sweetpotato and tomato similarly responded to $S_{0}$, carbon partitioning and thereby soluble sugar and starch concentrations may have been different between species.

Sugar CONCENTRATION AND MEDIUM VOLUME. During autoclaving, a portion of the original suc present was hydrolyzed to gluc and fruc in all media containing sugar. Specific sugar concentrations after autoclaving were $6.5,14.4$, and $29.5 \mathrm{~g} \cdot \mathrm{L}^{-1}$ for suc; $0.7,1.0$, and $1.4 \mathrm{~g} \cdot \mathrm{L}^{-1}$ for gluc; and $0.7,1.1$, and 1.4 $\mathrm{g} \cdot \mathrm{L}^{-1}$ for fruc at $S_{0}$ of $7.5,15$ and $30 \mathrm{~g} \cdot \mathrm{L}^{-1}$, respectively. The increase in total sugar (suc, gluc, and fruc) concentrations after autoclaving was $5 \%$ to $10 \%$. This indicates that, in addition to hydrolysis of suc, a small portion of water may have evaporated from the vessel during autoclaving or condensed on the inner wall of the vessel, resulting in an increase in the total sugar concentration.

After day 20 (sweetpotato) and 15 (tomato), suc still comprised the majority of the sugar in the medium and it was 4.8, 9.2, and 20.0 $\mathrm{g} \cdot \mathrm{L}^{-1}$ for sweetpotato; and 3.1, 7.8, and $17.3 \mathrm{~g} \cdot \mathrm{L}^{-1}$ for tomato at $S_{0}$ of $7.5,15$ and $30 \mathrm{~g} \cdot \mathrm{L}^{-1}$, respectively (Fig. 2). No sugar was detected in the medium without suc. All sugar concentrations at the end of culture increased with increasing $S_{0}(P$ linear $\leq 0.01)$. Medium volume at the end of culture was not affected by $S_{0}$, and was $15 \%$ to $20 \%$ less in sweetpotato and $13 \%$ to $16 \%$ less in tomato than the initial volume (data not shown). Based on the suc, gluc, and fruc concentrations and residual medium volume, the total mass of sugar left in the medium was $77 \%, 87 \%$, and $99 \%(0.58,1.31$, and $2.96 \mathrm{~g} /$ vessel $)$ of the initial values $(0.75,1.5$, and $3.0 \mathrm{~g} / \mathrm{vessel})$ for sweetpotato; and $64 \%, 82 \%$, and $85 \%(0.48,1.23$, and $2.54 \mathrm{~g} / \mathrm{vessel})$ for tomato at $S_{0}$ of $7.5,15$, and $30 \mathrm{~g} \cdot \mathrm{L}^{-1}$, respectively. Although the culture period for tomato was shorter than that for sweetpotato, more sugar remained in the medium for sweetpotato than for tomato. The low consumption of sugar (most sugar remained unconsumed in the medium) was probably due to $\mathrm{CO}_{2}$ enrichment and high $P P F$ that promoted photosynthesis by the cultured plantlets. Under conditions with lower $P P F$ and more limited $\mathrm{CO}_{2}$ (without $\mathrm{CO}_{2}$ enrichment and/or lower ventilation of the vessel), the plantlets may rely more on sugar in the medium as the major carbon source, and the sugar consumption would be higher than those in the present experiment. This hypothesis had been confirmed for tomato in a separately conducted experiment (Ezawa, 1997), where tomato plantlets were cultured under low $P P F\left(100 \mu \mathrm{mol} \cdot \mathrm{m}^{-2} \cdot \mathrm{s}^{-1}\right)$ in vessels with a low number of air exchanges $\left(1.6 \mathrm{~h}^{-1}\right)$. Under these conditions, the plantlets absorbed $32 \%$ of initial sugar when cultured at 30 $\mathrm{g} \cdot \mathrm{L}^{-1}$ of $S_{0}$, while they absorbed $15 \%$ of initial sugar at the same $S_{0}$

Fig. 3. Simulated changes in $\mathrm{CO}_{2}$ concentration $\left(C_{i n}\right)$ inside a vessel containing four tomato plantlets without sugar in the medium $\left(S_{0}=0\right)$. The $C_{i n}$ during light and dark periods was assumed to decrease/increase linearly and reach steady state conditions 1 and $6 \mathrm{~h}$, respectively, after onset of the period. $\mathrm{CO}_{2}$ concentration outside the vessel was $2050 \mathrm{mmol} \cdot \mathrm{mol}^{-1}$ throughout the culture period.

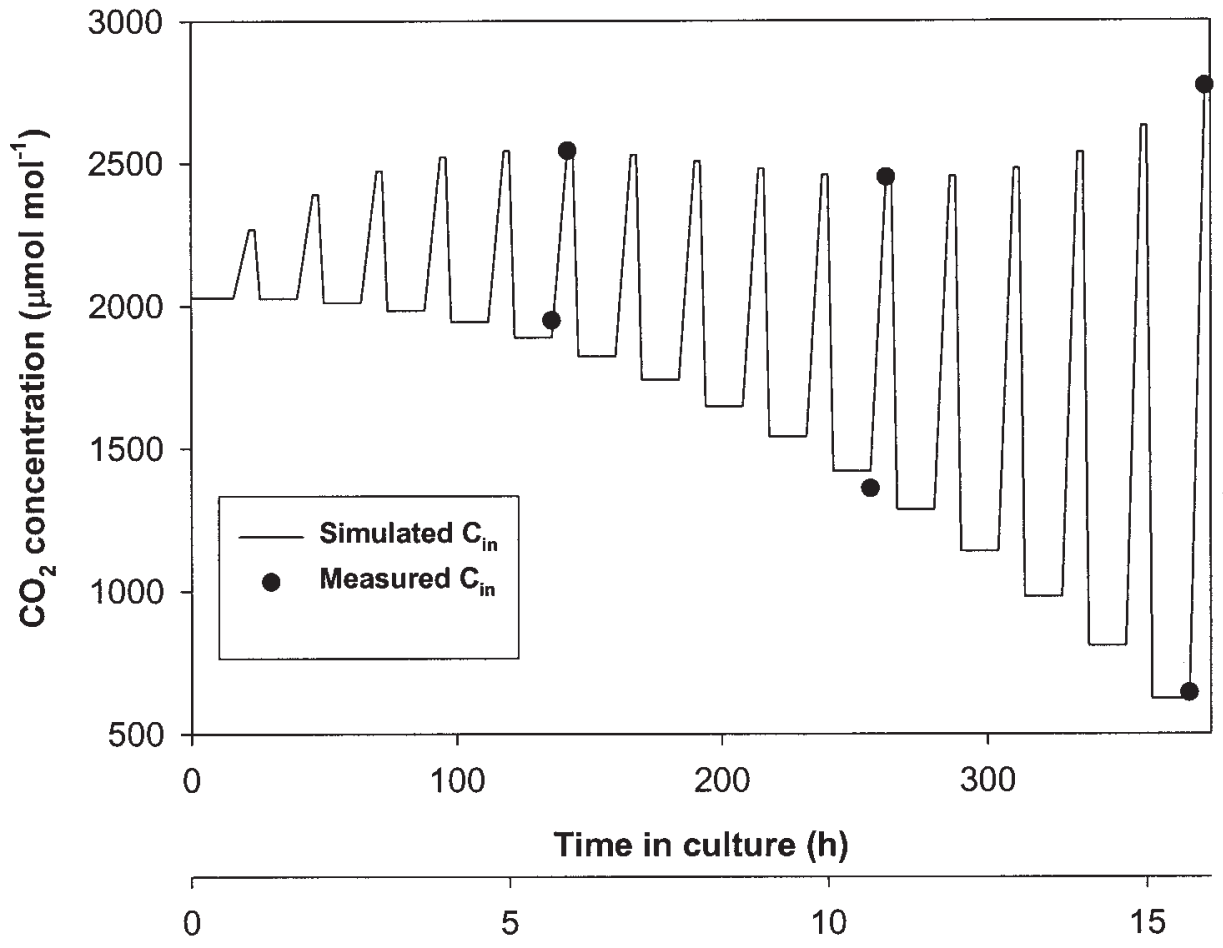

Time in culture (d) 
Table 2. Carbon balance of sweetpotato and tomato plantlets as affected by initial sucrose concentration of the medium $\left(S_{0}\right)$. Absorbed mole carbon by sugar uptake from medium, $U_{s}$, and by photosynthesis, $U_{p}$; Moles of carbon released by dark respiration, $L_{d}$, and by photorespiration, $L_{p}$; Percent contribution of photosynthesis, $\% P\left[\% P=100 \times U_{p} /\left(U_{s}+U_{p}\right)\right]$.

\begin{tabular}{|c|c|c|c|c|c|}
\hline \multirow[b]{2}{*}{$S_{0}$} & \multicolumn{2}{|c|}{$\begin{array}{l}\text { Absorbed carbon } \\
\text { (mmol C/plantlet) }\end{array}$} & \multirow{2}{*}{$\begin{array}{c}\text { Contribution }^{\mathrm{z}} \\
\% P \\
\end{array}$} & \multicolumn{2}{|c|}{$\begin{array}{l}\text { Released carbon } \\
\text { (mmol C/plantlet) }\end{array}$} \\
\hline & $U_{s}$ & $U_{p}$ & & $L_{d}$ & $L_{p}$ \\
\hline 0 & 0.0 & 6.2 & 100 & 2.7 & 0.93 \\
\hline 7.5 & 1.6 & 6.9 & 82 & 3.7 & 1.04 \\
\hline 15 & 1.9 & 6.2 & 77 & 3.2 & 0.92 \\
\hline $\mathrm{L}$ & $* *$ & NS & $* *$ & NS & NS \\
\hline Q & NS & $*$ & $* *$ & NS & $*$ \\
\hline \multicolumn{6}{|c|}{ Tomato for 15 days $(n=5)$} \\
\hline 0 & 0.0 & 3.6 & 100 & 2.0 & 0.54 \\
\hline 7.5 & 2.4 & 5.0 & 67 & 3.0 & 0.75 \\
\hline Q & $* *$ & $* *$ & $* *$ & $* *$ & $* *$ \\
\hline
\end{tabular}

${ }^{\mathrm{Z}}$ Data (percentage) were transformed by arcsinebefore analysis.

*,*** Significance at $P \leq 0.05$ or 0.01 , respectively; L or Q indicates linear or quadratic response, respectively.

under a high number of air exchanges $\left(4.7 \mathrm{~h}^{-1}\right)$ and high $P P F(160$ $\left.\mu \mathrm{mol} \cdot \mathrm{m}^{-2} \cdot \mathrm{s}^{-1}\right)$.

STEADY STATE $\mathrm{CO}_{2}$ CONCENTRATION INSIDE THE VESSEL $\left(\mathrm{C}_{\mathrm{IN,S}}\right)$ AND ESTIMATION OF CHANGES IN $\mathbf{C}_{\mathrm{IN}}$ DURING CULTURE. In both plant species, $C_{i n, s}$ measured during the light period decreased with time, except for sweetpotato during days 5 to 10 (Table 1). Increased $C_{i n, s}$ during the light period in sweetpotato for days 5 to 10 was due to an increase in $C_{\text {out }}$ (from $1400 \mu \mathrm{mol} \cdot \mathrm{mol}^{-1}$ on day 5 to 1800 $\mu \mathrm{mol} \cdot \mathrm{mol}^{-1}$ on day 6 ). Although differences among $S_{0}$ were relatively small, $C_{i n, s}$ during the light period increased with increasing $S_{0}$ $(P$ linear $\leq 0.01)$, except for tomato on days 10 and 15 in which no significant influence of $S_{0}$ was observed. The $C_{i n, s}$ attained a range of 250 to $390 \mu \mathrm{mol} \cdot \mathrm{mol}^{-1}$ in sweetpotato and 450 to $890 \mu \mathrm{mol} \cdot \mathrm{mol}^{-1}$ in tomato by the end of culture. The $C_{i n, s}$ measured during the dark period increased with time in sweetpotato. The $S_{0} \operatorname{did}$ not affect $C_{i n, s}$ during the dark period except for day 15 . In tomato, $C_{i n, s}$ during the dark period increased with time regardless of $S_{0}$ except for $0 \mathrm{~g} \cdot \mathrm{L}^{-1}$, and with increasing $S_{0}(P$ linear $\leq 0.01)$.

The time course of changes in $C_{i n}$ was simulated for each vessel based on the measured $C_{i n, s}$ by our assumptions (Fig. 3). The $C_{i n}$ during the dark period was simulated as reaching steady state conditions $6 \mathrm{~h}$ after initiation of the dark period, although changes in $C_{i n}$ during the dark period did not affect the estimation of cumulative $\mathrm{CO}_{2}$ exchange rates since the $R_{d}$ was assumed to be constant. Simulated results were considered representative of the typical changes in $C_{\text {in }}$ of the vessels containing plantlets under natural ventilation conditions.

Plantlet Carbon balances. The $S_{0}$ affected $U_{s}, U_{p}, \% P$, and $L_{p}$, but did not affect $L_{d}$ for sweetpotato (Table 2). The $\% P$ decreased and attained $77 \%$ to $92 \%$ when suc was added to the medium. For tomato plantlets, $S_{0}$ affected $U_{s}, U_{p}, \% P, L_{d}$, and $L_{p}(P$ quadratic $\leq$ 0.01 ). The $\% P$ decreased with $S_{0}$, and attained $60 \%$ to $67 \%$ for $S_{0}$ of 7.5 to $30 \mathrm{~g} \cdot \mathrm{L}^{-1}$. When the plantlets were cultured with sugar in the medium, the range of $U_{s}$ was relatively higher for tomato (2.4 to 4.5 mmol C per plantlet) than for sweetpotato (0.6 to $1.6 \mathrm{mmol} \mathrm{C}$ per plantlet), while $W_{d}$ was relatively higher for sweetpotato (133 to 136 mg per plantlet) than for tomato (67 to $99 \mathrm{mg}$ per plantlet). This observation corresponded to the higher $\% P$ for sweetpotato $(77 \%$ to $92 \%$ ) than for tomato ( $60 \%$ to $67 \%$ ).

Mole fractions of $U_{s}$ to the carbon added as sugar in the medium $(6.5,13$, and $26 \mathrm{mmol} \mathrm{C}$ per plantlet were added at $7.5,15$, and 30 $\mathrm{g} \cdot \mathrm{L}^{-1}$ of $S_{0}$, respectively) can be considered as indicating the sugar utilization efficiency, and were $0.25,0.14$, and $0.02 \mathrm{~mol} \cdot \mathrm{mol}^{-1}$ for sweetpotato; and $0.37,0.20$, and $0.17 \mathrm{~mol} \cdot \mathrm{mol}^{-1}$ for tomato at 7.5 , 15 , and $30 \mathrm{~g} \cdot \mathrm{L}^{-1}$ of $S_{0}$, respectively, decreasing with increasing $S_{0}$. In R. multiflora, $50 \%$ to $75 \%$ of tissue carbon was derived from sugar uptake from the medium; however, $68 \%$ to $84 \%$ of sugar taken up from the medium was used for respiration (De Riek et al., 1991). Borkowska and Kubik (1990), using ${ }^{14} \mathrm{C}$-suc, showed that sour cherry (Prunus cerasus L.) plantlets absorbed $23 \%$ of sugar added to the medium but only $5 \%$ of the original activity of the medium remained in dry weight, indicating that most of the carbon absorbed as sugar from the medium had been respired. In the present experiment, the ratios of $L_{d}$ to $U_{p}$ increased with increasing $S_{0}(0.44,0.54$, 0.52 , and 0.56 for sweetpotato; $0.56,0.60,0.66$, and 0.78 for tomato at $S_{0}$ of $0,7.5,15$, and $30 \mathrm{~g} \cdot \mathrm{L}^{-1}$, respectively), indicating increased $R_{d}$ with increasing $S_{0}$. High dark respiration rates have been reported for many species when cultured with sugar in the medium (Cristea et al., 1999; Galzy and Compan, 1992; Kubota et al., 2001). If the sugar taken up from the medium merely enhances the dark respiration rate and is mostly released as $\mathrm{CO}_{2}$ to the atmosphere, addition of sugar in the medium reduces the efficiencies of energy and sugar incorporated to dry matter in plantlets, especially chlorophyllous plantlets that have already gained photosynthetic ability.

The higher $\% P$ in sweetpotato than in tomato suggests that controlled environments (e.g., $\mathrm{CO}_{2}$ enrichment and increased $P P F$ ) can more effectively enhance the dry weight increase of sweetpotato plantlets, but that increasing sugar concentration in addition to $\mathrm{CO}_{2}$ enrichment and increased PPF may be necessary to effectively increase dry weight of tomato plantlets. De Riek et al. (1991) used ${ }^{14} \mathrm{C}$-labeled suc and ${ }^{14} \mathrm{CO}_{2}$ to show that $75 \%$ of the dry weight carbon originated from suc ( $25 \%$ was from photosynthesis) for rose plant- 


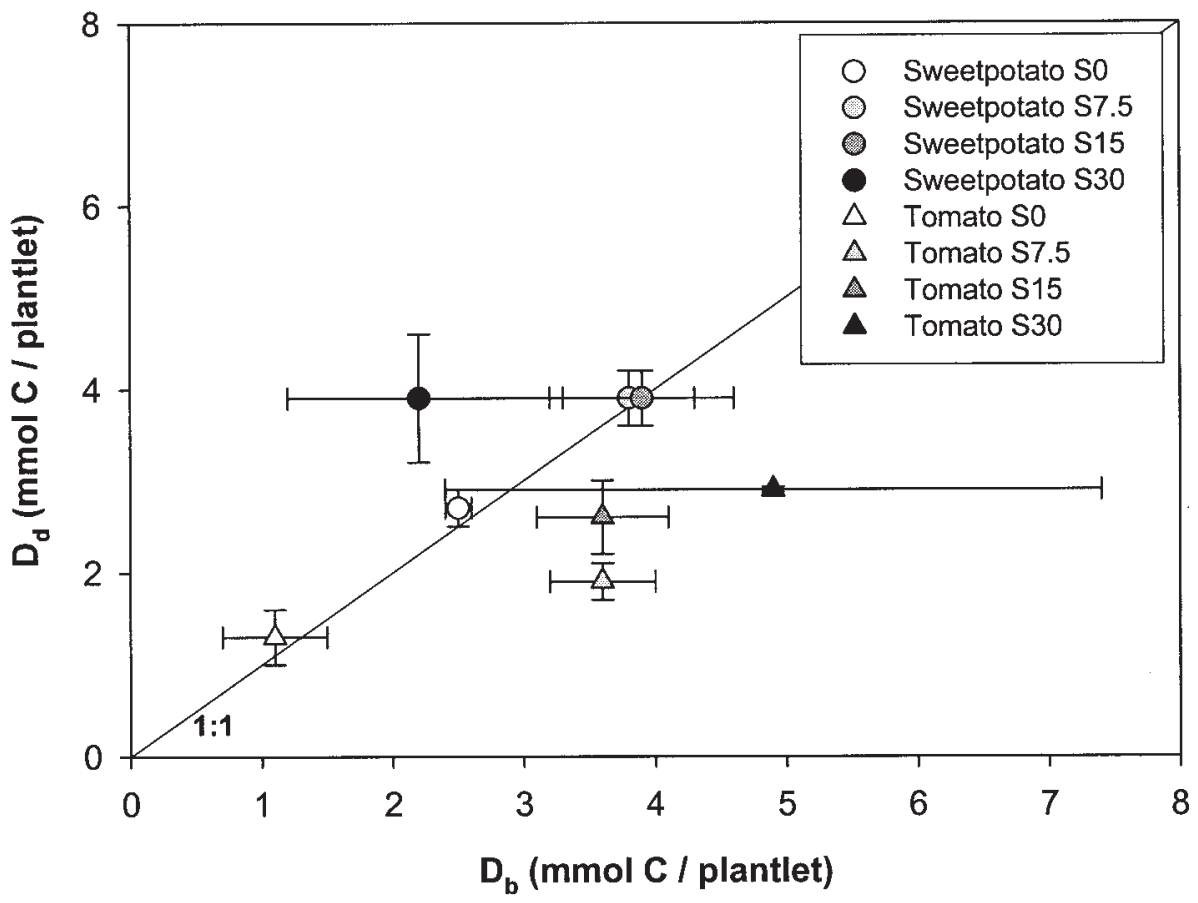

Fig. 4. Increase of moles of carbon per plantlet calculated from the balance equation, $D_{b}\left(D_{b}=U_{s}+U_{p}-L_{d}-L_{p}\right)$, and from dry weight increase, $D_{d} U_{s}$ and $U_{p}$ are absorbed mole carbon by sugar uptake from medium and by photosynthesis, respectively; $L_{d}$ and $L_{p}$ are released mole carbon by dark respiration and by photorespiration, respectively. Means \pm sD are shown $(n=6$ and 5 for sweetpotato and tomato, respectively).

lets cultured with $30 \mathrm{~g} \cdot \mathrm{L}^{-1}$ suc under low PPF $\left(35 \mu \mathrm{mol} \cdot \mathrm{m}^{-2} \cdot \mathrm{s}^{-1}\right)$ without $\mathrm{CO}_{2}$ enrichment (conventional culture conditions). This percentage varied with different cultivars within the same species. Lower sugar concentrations (Serret et al., 1997; Wolf et al., 1998) and osmotic potentials (Wolf et al., 1998) increased percent tissue carbon derived from photosynthesis of photomixotrophic plantlets. The percentage of tissue carbon derived from photosynthesis of potato plantlets was about $40 \%$ when cultured at $30 \mathrm{~g} \cdot \mathrm{L}^{-1}$ suc, while it was only $10 \%$ at $80 \mathrm{~g} \cdot \mathrm{L}^{-1}$ suc (Wolf et al., 1998).

Effects of physical environmental conditions on percent carbon derived from photosynthesis over the total carbon in dry weight have been well studied in gardenia. Gardenia plantlets at shoot multiplication stage were shown to have $36 \%$ photosynthates in leaflet dry matter when cultured in tightly sealed vessels, but $93 \%$ when cultured in loosely sealed vessels (Serret et al., 1997). Increasing $P P F$ from 50 to $300 \mu \mathrm{mol} \cdot \mathrm{m}^{-2} \cdot \mathrm{s}^{-1}$ increased this percentage from $16 \%$ to $56 \%$ for the gardenia leaflets (Serret et al., 1996). Our preliminary data for tomato plantlets (Ezawa, 1997) cultured under $100 \mu \mathrm{mol} \cdot \mathrm{m}^{-2} \cdot \mathrm{s}^{-1}$ and 1.6 air exchanges $/ \mathrm{h}$ in the vessel showed that contribution of photosynthesis $(\% P)$ was $24 \%$ when cultured at 30 $\mathrm{g} \cdot \mathrm{L}^{-1}$ suc, while it was $60 \%$ at the same suc level under 160 $\mu \mathrm{mol} \cdot \mathrm{m}^{-2} \cdot \mathrm{s}^{-1}$ and 4.7 air exchanges $/ \mathrm{h}$. Under conventional culture conditions (lower $P P F$ and less ventilation), plantlets are generally dependent on sugar in the medium mainly due to limited availability of $\mathrm{CO}_{2}$ in the head space and thereby the $\% P$ is expectedly smaller. Fujiwara et al. (1995) showed that the contribution from photosynthesis to dry weight increase, expressed as mass of carbohydrate on a basis of plantlet dry weight increase, was three to four times greater than the contribution from sugar taken up from the medium for potato plantlets cultured at $15 \mathrm{~g} \cdot \mathrm{L}^{-1}$ initial suc concentration under $100 \mu \mathrm{mol} \cdot \mathrm{m}^{-2} \cdot \mathrm{s}^{-1} \mathrm{PPF}$ and $1000 \mu \mathrm{mol} \cdot \mathrm{mol}^{-1} \mathrm{CO}_{2}$ concentration.
This result agrees with those obtained by us for sweetpotato at $15 \mathrm{~g} \cdot \mathrm{L}^{-1}$ of $S_{0}$ (the ratio of $U_{s}$ to $U_{p}$ was 3.3). In the present experiment, the $\% P$ can be further increased for both species by increasing $\mathrm{CO}_{2}$ concentration and $P P F$ inside the vessel.

Validation of the increase of moles of carbon per plantlet showed that the estimation using the carbon balance equation was reasonably accurate for plantlets cultured without sugar in the medium $\left(S_{0}=0\right)$, regardless of species. This conclusion indicates that the assumptions made for simulating $C_{i n}$ and estimating cumulative photosynthesis and respiration were acceptable for no sugar in the medium. For sweetpotato plantlets, increased moles of carbon per plantlet, calculated according to the carbon balance equation $\left(D_{b}\right)$, generally agreed with the increased moles of carbon calculated from the dry weight increase $\left(D_{d}\right)$ except at the highest $S_{0}$ of $30 \mathrm{~g} \cdot \mathrm{L}^{-1}$ (Fig. 4) where the $D_{b}$ were underestimated. For tomato plantlets, $D_{b}$ agreed with $D_{d}$ only at no sugar $\left(S_{0}=0 \mathrm{~g} \cdot \mathrm{L}^{-1}\right)$, and was overestimated when cultured with sugar in the medium. The disagreement of $D_{b}$ and $D_{d}$ for tomato may be due to overestimation of photosynthetic carbon uptake $\left(U_{p}\right)$ as indicated by Fujiwara et al. (1995). Dark respiration rate for plantlets cultured with sugar in the medium includes $\mathrm{CO}_{2}$ through dissimilation of sugar in the medium. Therefore the present estimate of $U_{p}$ based on the $\mathrm{CO}_{2}$ exchange rate measured during light and dark periods may be an overestimate. For tomato, the differences between $D_{b}$ and $D_{d}$ were 1.7, 1.0, and 2.0 mmol C per plantlet at $7.5,15$, and $30 \mathrm{~g} \cdot \mathrm{L}^{-1}$ of $S_{0}$, which accounted for $40 \%$ to $70 \%$ of $U_{s}$. This finding may indicate that a significant portion of sugar absorbed from the medium was released as $\mathrm{CO}_{2}$, as reported for other species under conventional culture conditions (Borkowska and Kubik, 1990; De Riek et al., 1991). If the $40 \%$ to $70 \%$ of $U_{s}$ were respired as $\mathrm{CO}_{2}, 37 \%$ to $86 \%$ of dry weight carbon originated from suc (14\% to $63 \%$ from photosynthesis) [e.g., (2.4$1.7) / 1.9=0.37$ at $7.5 \mathrm{~g} \cdot \mathrm{L}^{-1}$ of $\left.S_{0}\right]$. For sweetpotato, there was little difference between $D_{b}$ and $D_{d}$ except at $30 \mathrm{~g} \cdot \mathrm{L}^{-1}$ of $S_{0}$. This finding may indicate that the majority of suc taken up from the medium remained in plant tissue without its release as $\mathrm{CO}_{2}$. In this case, $15 \%$ to $49 \%$ of dry weight carbon originated from suc for sweetpotato. The relatively lower $L_{d} / U_{p}$ ratio in sweetpotato than tomato shows that sweetpotato respired less $\mathrm{CO}_{2}$ than did tomato per fixed mole of carbon, which may also indicate that less carbon from medium suc was released in sweetpotato than in tomato. If $U_{p}$ was overestimated at high $S_{0}$ in tomato in the present experiment, actual $U_{p}$ and $\% P$ may be lower than the presented values for tomato.

Another reason that could explain underestimation/overestimation is the possible diurnal changes in net photosynthetic and dark respiration rates, which were assumed to be at steady state for most of the time during the light and dark periods in the present study. Overestimation of photosynthesis and/or underestimation of dark respiration can lead to the overestimation of $D_{b}$, and underestimation of photosynthesis and/or overestimation of dark respiration can cause an underestimation of $D_{b}$. Diurnal changes in respiratory $\mathrm{CO}_{2}$ release have been shown in many plant species including in vitro callus cultured in darkness (Wilkins and Holowinsky, 1965). There is also ample evidence that the level of carbon substrate in tissue is positively correlated with plant respiration rate (Amthor, 1989) and 
photosynthesis (Foyer and Galtier, 1996). The high $S_{0}$ could enhance the carbohydrate concentration of the plantlets and thereby alter the diurnal changes in $\mathrm{CO}_{2}$ exchange rates.

Nonphotosynthetic carbon fixation by phosphoenolpyruvate carboxylase (PEPC) has been reported for in vitro plantlets (Desjerdins et al., 1995). However, PEPC activity was not determined in the present experiment. Desjardins et al. (1995) found high PEPC activity when sugar was added to the medium for early growth stages of strawberry plantlets. A nonnegligible amount of $\mathrm{CO}_{2}$ fixation by PEPC may cause overestimation of $\% P$, but further biochemical work is needed to separate photosynthetic and nonphotosynthetic carbon fixation.

The carbon balance of in vitro plantlets was estimated in situ with reasonable accuracy when grown with an initial medium suc concentration of 0 to $15 \mathrm{~g} \cdot \mathrm{L}^{-1}$ for sweetpotato and with no suc for tomato. Tomato plantlets were more dependent on sugar in the medium than sweetpotato. For both sweetpotato and tomato, the dry weight increased, but the net photosynthetic rate during the light period and the efficiency of sugar use from the medium decreased with increasing initial suc concentrations. Such analysis of carbon balance and use of resources for tissue culture is crucial for a better understanding of carbon metabolism in vitro and for selection and improvement of methods and systems for micropropagation.

\section{Literature Cited}

Afreen-Zobayed, F., S.M.A. Zobayed, C. Kubota, T. Kozai, and O. Hasegawa. 1999. Supporting material affects the growth and development of in vitro sweetpotato plantlets cultured photoautotrophically. In Vitro Cell. Dev. Biol. Plant 35:470-474.

Amthor, J.S. 1989. Respiration and crop productivity. Springer-Verlag, New York.

Borkowska, B. and M. Kubik. 1990. Utilization and accumulation of ${ }^{14} \mathrm{C}$ sucrose in sour cherry shoots rooted in vitro. Scientia Hort. 44:261-267.

Cappellades, M., R. Lemeur, and P. Debergh. 1991. Effects of sucrose on starch accumulation and rate of photosynthesis in Rosa cultured in vitro. Plant Cell Tissue Org. Cult. 25:21-26.

Cristea, V., F. Dalla Vecchia, and N. La Rocca. 1999. Development and photosynthetic characteristics of a photoautotrophic Chrysanthemum culture. Photosynthetica 37:53-59.

De Riek, J., O. Van Cleemput, and P.C. Debergh. 1991. Carbon metabolism of micropropagated Rosa multiflora L. In Vitro. Cell. Dev. Biol. Plant 27:57-63.

Desjardins, Y., C. Hdider, and J. De Riek. 1995. Carbon nutrition in vitro. Regulation and manipulation of carbon assimilation in micropropagated systems, p. 441-447. In: J. Aitken-Christie, T. Kozai, and M.A.L. Smith (eds.). Automation and environmental control in plant tissue culture. Kluwer Academic, The Netherlands.

Desjardins, Y., F. Laforge, C. Lussier, and A. Gosselin. 1988. Effect of CO enrichment and high photosynthetic photon flux on the development of autotrophy and growth of tissue-cultured strawberry, raspberry and asparagus plants. Acta Hort. 230:45-53.

Ezawa, M. 1997. Effects of initial sucrose concentration in the medium on the growth of plantlets cultured in vitro (in Japanese with English figures and tables). BS thesis, Chiba University, Japan.

Fournioux, J.-C. and R. Bessis. 1986. Influence de la teneur en gaz carbonique sur la morphogénèse en culture in vitro. Can. J. Bot. 64:26082616.

Foyer, C.H. and N. Galtier. 1996. Sucrose-sink interaction and communication in leaves, p. 311-340. In: E. Zamski and A.A. Schaffer (eds.). Photoassimilate distribution in plants and crops: Source-sink relationships. Marcel Dekker, New York.

Fujiwara, K. and T. Kozai. 1995. Physical microenvironment and its effects, p. 319-369. In: J. Aitken-Christie, T. Kozai, and M.A.L. Smith (eds.). Automation and environmental control in plant tissue culture. Kluwer Academic, The Netherlands.
Fujiwara, K., S. Kira, and T. Kozai. 1995. Contribution of photosynthesis to dry weight increase of in vitro potato cultures under different $\mathrm{CO}_{2}$ concentrations. Acta Hort. 393:119-126.

Fujiwara, K., T. Kozai, and I. Watanabe. 1987. Fundamental studies on environments in plant tissue culture vessels. III. Measurements of carbon dioxide gas concentration in closed vessels containing tissue cultured plantlets and estimates of net photosynthetic rates of the plantlets (in Japanese with English summary, figures and tables). J. Agr. Meteorol. 43:21-30.

Galzy, R. and D. Compan. 1992. Remarks on mixotrophic and autotrophic carbon nutrition of Vitis plantlets cultured in vitro. Plant Cell Tissue Organ Cult. 31:239-244.

Infante, R., E. Magnanini, and B. Righetti. 1989. The role of light and $\mathrm{CO}_{2}$ in optimizing conditions for shoot proliferation of Actinidia deliciosa in vitro. Physiol. Plant. 77:191-195.

Kozai, T. 1991. Autotrophic micropropagation, p. 313-343. In: Y.P.S. Bajaj (ed.). Biotechnology in agriculture and forestry. vol. 17. SpringerVerlag, New York.

Kozai, T. and K. Sekimoto. 1988. Effects of the number of air exchanges per hour of the closed vessel and the photosynthetic photon flux on the carbon dioxide concentration inside the vessel and the growth of strawberry plantlets in vitro (in Japanese with English abstract, figures and tables). Environ. Control Biol. 26:21-29.

Kozai, T., K. Fujiwara, and I. Watanabe. 1986. Fundamental studies on environments in plant tissue culture vessels. II. Effects of stoppers and vessels on gas exchange rates between inside and outside of vessels closed with stoppers (In Japanese with English summary, figures and tables). J. Agric. Meteorol. 42:119-127.

Kubota, C., K. Kakizaki, T. Kozai, K. Kasahara, and J. Nemoto. 2001. Growth and net photosynthetic rate of tomato plantlets during photoautotrophic and photomixotrophic micropropagation. HortScience 36:49-52.

Langford, P.J. and H. Wainwright. 1987. Effect of sucrose concentration on the photosynthetic ability of rose shoots in vitro. Ann. Bot. 60:633640.

Murashige, T. and F. Skoog. 1962. A revised medium for rapid growth and bioassays with tobacco tissue cultures. Physiol. Plant. 15:473-497.

Murayama, N. T. Hirata, H. Yazaki, T. Tano, T. Horiguchi, N. Shimada, and K. Maeda. 1984. Plant nutrition (in Japanese). Buneido, Tokyo.

Pageau, K., P. Simier, N. Naulet, R. Robins, and A. Fer. 1998. Carbon dependency of the hemiparasite Striga hermonthica on Sorghumbiocolor determined by carbon isotopic and gas exchange analyses. Austral. J. Plant Physiol. 25:695-700.

Piqueras, A., J.M. Van Huylenbroeck, B.H. Han, and P.C. Debergh. 1998. Carbohydrate partitioning and metabolism during acclimatization of micropropagated Calathea. Plant Growth Regul. 26:25-31.

Pospisilova, J., J. Solarova, and J. Catsky. 1992. Photosynthetic responses to stress during in vitro cultivation. Photosynthetica 26:3-18.

Serret, M.D., M.I. Trillas, J. Matas, and J.L. Araus. 1996. Development of photoautotrophy and photoinhibition of Gardenia jasminoides plantlets during micropropagation. Plant Cell Tissue Organ Cult. 45:116.

Serret, M.D., M.I. Trillas, J. Matas, and J.L. Araus. 1997. The effect of different closure types, light, and sucrose concentrations on carbon isotope composition and growth of Gardenia jasminoides plantlets during micropropagation and subsequent acclimatization ex vitro. Plant Cell Tissue Organ Cult. 47:217-230.

Wilkins, M.B. and A.W. Holowinsky. 1965. The occurrence of an endogenous circadian rhythm in a plant tissue culture. Plant Physiol. 40:907-909.

Wilson, S.B., C. Kubota, and T. Kozai. 2000. Effects of medium sugar on growth and carbohydrate status of sweetpotato and tomato plantlets in vitro, p. 258-265. In: C. Kubota and C. Chun (eds.). Transplant production in the 21 st century. Kluwer Academic Publishers, The Netherlands.

Wolf, S., N. Kalman-Rotem, D. Yakir, and M. Ziv. 1998. Autotrophic and heterotrophic carbon assimilation of in vitro grown potato (Solanum tuberosum L.) plants. J. Plant Physiol. 153:574-580. 